\title{
Advanced seismic investigations during construction of hydro tunnels
}

\author{
Thomas Dickmann and J Hecht-Méndez \\ Amberg Technologies AG \\ Regensdorf, Switzerland \\ tdickmann@amberg.ch
}

\author{
Kripal Choudhary \\ Amberg Engineering AG \\ Gurgaon, India
}

\author{
Ataollah Rahbar \\ Farab Company \\ Colombo, Sri Lanka
}

\begin{abstract}
In order to maintain the economic and safety demand in underground projects for hydropower there is a vital necessity of advance geological prediction by using the seismic reflection prediction technique. Tunnelling in many projects suffered due to uncertain or even unknown geological problems such as fault and shear zones, cavities and ingress of water and high level of seismicity etc. By recording the full wave-field of reflected signals, $P$ - and $S$-waves, prediction of the rock mass quality in term of physical and mechanical parameters up to $150 \mathrm{~m}$ ahead of the face is possible. Moreover, 3D velocity distribution images are generated by means of seismic modelling. Results of surveys performed at the Uma Oya Multipurpose Development Project in Sri Lanka using this technology are discussed. Here, the headrace tunnel of $15 \mathrm{~km}$ length is under construction using a shield TBM. Although installing pre-cast segments behind the cutter head, seismic investigation become still manageable and provide an important impact on logistic optimization that could end up in an economic and consequentially time- and cost-effective practice of prediction ahead.
\end{abstract}

Keywords-Tunnel Seismic Prediction; Rock Characterisation; Geological Forecast

\section{INTRODUCTION}

Hydropower projects are the best source for power generation due to pollution free and renewable nature, moreover, it is the most widely used renewable energy worldwide and it covers up to approximately $16 \%$ of the global energy consumption with an annual increasing trend [1]. Independently of the type of hydropower development, tunnels are common infrastructures to these projects in many applications such as: diversion tunnels (intakes, outlets), headrace and tailrace tunnels and access and connection tunnels.

Due to the recurrent increment of energy demand and the advances in excavation methods, nowadays, hydro tunnels are becoming longer, deeper and with higher diameter. In addition, such projects are in many cases located in remote areas with challenging conditions such as mountainous areas, higher overburden, and difficult accessibility. Hence, prior geological characterisation along the design tunnel alignment is limited and more assumptions and projections are made which finally become a cause of concern for projects' owners and contractors during execution.

In order to minimise the geological uncertainty and to avoid unpredicted risks, geological prediction during tunnelling should be a normal practice in order to complete the project within the stipulated time and as safe as possible. In fact, the key to success or failure of any tunnelling project is quality of rock mass that tunnel passes through and the rock support measures that are being applied during excavation. In this respect, accurate evolution, analysis and interpretation of rock mass quality plays a significant role.

The most common practice for geological characterisation during tunnelling is systematic probe drilling, however, this type of exploration technique is associated to higher costs mainly due to operative downtimes and, short investigation range $(<50 \mathrm{~m})$. Alternatively, geophysical investigations from the face based on seismic methods allow covering a larger range and delivers 3D spatial information about the rock mass properties.

The geological risk involved during excavation of hydro tunnels and the application of 3D geological prediction by seismic investigations is therefore an interesting discussion. Tunnel Seismic Prediction (TSP) technology is a geophysical technique specially developed for tunnelling activities which helps avoid risks associated with poor rock strata [2]. Several TSP surveys had been carried out in different hydro tunnel projects worldwide covering a large range of rock types and conditions in both excavation methods: conventional and mechanised. The TSP method has helped in tunnelling activities from the Himalayas (e.g. 
Rohtang Pass Tunnel Project, India), the Alps (e.g. Gotthard Base Tunnel, Switzerland) to the Andes (e.g. Proyecto Especial Olmos, Peru).

In the present paper, results of two campaigns performed in the Uma Oya Multipurpose Development Project, Sri Lanka are presented and TSP prognosis is compared with actual geology after excavation. To date more than 26 TSP measurements have been performed at the headrace tunnel of this challenging project resulting in more than $3,500 \mathrm{~m}$ of prediction range.

\section{APPLICATION OF GEOLOGICAL PREDICTION}

Among various constraints causing delay in hydropower projects, inaccessible terrain and adverse/uncertain geological condition are most common. Due to the limited geological characterisation prior to the excavation, ongoing rock mass exploration should be performed during the construction phase. By combining different tools, e.g. geological mapping, probe drills and long range prediction, the initial geological conceptual model can be updated according to a model-driven interpretation workflow Fig. 1 [3].

Non-destructive geophysical site investigations while tunnelling are a reliable tool for long range predictions. The TSP technology copes very well this task, since it provides reliable results up to $150 \mathrm{~m}$ ahead of the face. In addition, it provides high resolution and allows for the estimation of rock mass mechanical properties based on the seismic wave velocities. Therefore by carrying out comprehensive 3D geological predication using TSP, geological uncertainties can be managed in favour of all parties involved.

\section{SEISMIC INVESTIGATION WHILE TUNNELLING}

Tunnel Seismic Prediction works as a predictive method during the excavation process for both, conventional and mechanised headings. Acoustic signals are produced by a series of 24 shots, containing small explosive charge as seismic source (commonly between 20 and $100 \mathrm{gr}$ ), which provide the best signal to noise ratio and the least restrictive conditions for recording and processing. Four sensor probes, consisting of highly sensitive tri-axial receivers, are contained in protection tubes whose tips are firmly cemented into boreholes in both side-walls Fig. 2.

The 3-component receivers pick up the seismic signals which have been reflected back from any kind of discontinuity in the rock mass ahead. The most recent TSP technology, the TSP 303 Plus system, allows recording the full wave field of compressional and shear waves. By analysing this wave field using the cutting edge TSP software, determination of rock mechanical properties such as Poison ratio and Young's modulus within the prediction range is possible. The final $2 \mathrm{D}$ and $3 \mathrm{D}$ summary result produced by the system software presents as well detected events and boundary planes crossing the tunnel axis coordinates ahead of face.

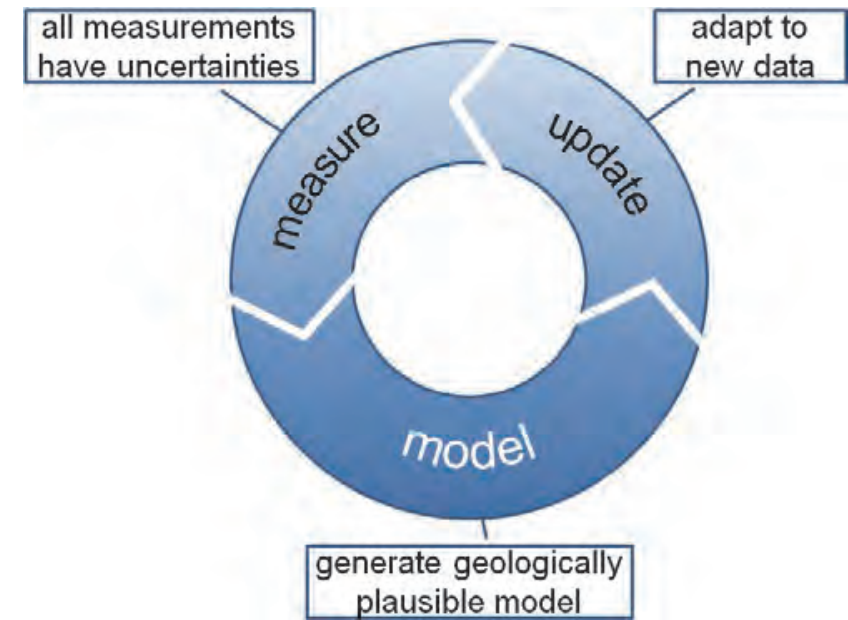

Fig. 1. Model-driven geological interpretation workflow

\section{A) Advantage and benefits of seismic investigations}

As mentioned before, seismic investigation provides the necessary long range prognosis valuable for minimising the geological uncertainty using model-driven interpretation. Besides the large prediction range and high resolution obtained by the TSP 303, the method provides also the following advantages:

- $3 \mathrm{D}$ spatial investigation ahead of the face.

- Detection of hazardous fault zones and cavities.

- Exploration of water bearing formation.

- Discovery of change in rock mechanical properties.

Advance knowledge of the spatial dimensions of geological fault zones, cavities, water bearing formations and changes in rock mechanical properties are key factors for a sound risk management, consistent operational safety and timely planning of construction countermeasures.

With regular tunnel seismic operation, hazardous areas can be identified as the excavation advances helping to quantifying their impact in the tunnelling project. By this means, tunnel builders can understand the risk as chance and in very economical way. Depending on heading length and type of heading, the investment in knowing the risk by a regular TSP operation is less than $2 \%$ of the time dependent site cost "Fig. 3". This percentage commonly represents the preventive downtime provision in a tunnel project. In other words, all investments in this technology are already paid after saving 3 to 7 days of downtime. Assuming a minimum length of $3 \mathrm{~km}$ for TBM excavation, a reduction of only 3 to 5 days of downtime pays off TSP operation on a regular basis.

\section{B) Assessment of groundwater bearing zones}

Investigations of groundwater conditions are very important for a successful completion of the tunnel work. Though it is difficult to judge the groundwater condition 


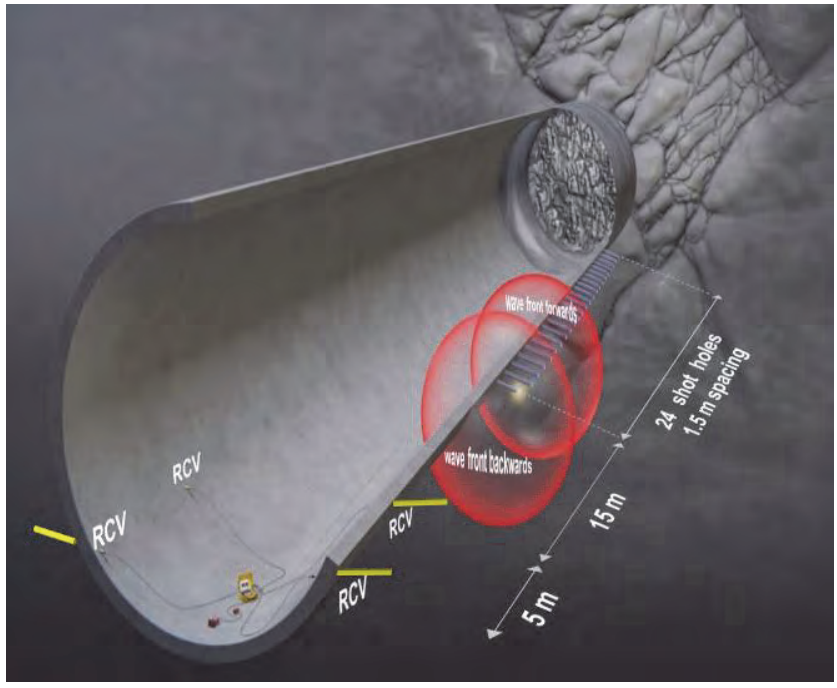

Fig. 2. Schematic view of a standard TSP layout

total costs of periodic TSP operation of every $120 \mathrm{~m}$ advance vs heading length

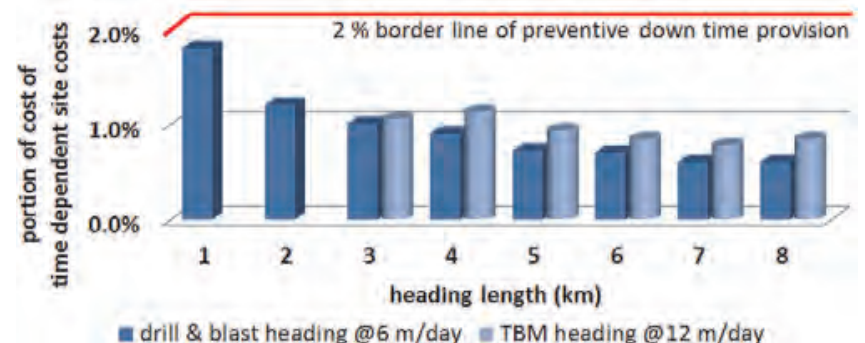

Fig. 3. Portion of TSP system costs as a function of the time-dependent site costs for various heading length according to the excavation method

during investigation stages, efforts are being made to probe simultaneously while advancing tunnel excavation in water charged zones by probe drilling and Tunnel Seismic Prediction. Detection of water bearing zone by meaning of seismic methods alone is limited, however, by a profound analysis of the variations of S-wave velocities $\left(V_{s}\right)$ and the Poisson ratio $(\sigma)$, good indications can be found. Using (1) and considering that $\mathrm{S}$-waves do not travel in fluids (i.e. $V_{s}$ $=0 \mathrm{~m} / \mathrm{s}$ ), then $\sigma$ is 0.5 . In (1) $V_{p}$ is the velocity of the Pwaves. Contrary, for rock mass, $\sigma$ varies between 0.2 and 0.3 (good to poor rock mass conditions). Experience with TSP results shows that exploration of water bearing formation is possible, in particular when estimated $\sigma>0.3$. However, the absolute value of the Poisson ratio as well as its correlation to water occurrence is not always straightforward and it will depend on the seismic response of the rock mass, the knowledge gained through the regular use of TSP and the interpreter's experience.

$$
\sigma=\frac{V_{p}^{2}-2 V_{s}^{2}}{2\left(V_{p}^{2}-V_{s}^{2}\right)}
$$

\section{C) Occurrence of shear/fractured zones}

Occurrence of deformed and crushed rock mass along tunnel route poses several obstructions during excavation like formation of cavities collapse, debris flow, etc.
Encountering such zones during excavation is common. In such cases, significant changes on the seismic wave velocities are expected and characterise by a decrease either in one of the wave type or in both (P- and S-waves). Zones were a decrease in the seismic wave velocity occurs are commonly defined as Low Velocity Zones (LVZ). In term of mechanical parameters, the dynamic Young modulus $\left(E_{d y n}\right)$, which is related to the rock mass stiffness, can be estimated using (2). Since it is directly derived from the wave velocities and rock mass density, it can be correlated to in situ rock mass conditions. Therefore, in case that the waves propagate through a LVZ, a decrease of $E_{d y n}$ might be also expected.

$$
E_{d y n}=\rho V_{s}\left(\frac{3 V_{p}^{2}-4 V_{s}^{2}}{V_{p}^{2}-V_{s}^{2}}\right)
$$

\section{CASe Study}

\section{D) Project overview}

The Uma Oya Multipurpose Development Project is a water transfer, hydropower and irrigation project in the south-eastern part of the central highland region of Sri Lanka initiated by the Ministry of Irrigation and Water Resources Management of Sri Lanka and contracted to Farab Company. The main part of the scheme is situated in the south-western part of the Badulla district in the province of Uva Fig. 4.

The project will transfer water for irrigation purpose and will serve as a power plant producing electricity with a rated capacity of about $120 \mathrm{MW}$. It consists of two RCC dams, whereof the first is to be built on Uma Oya River at Puhulpola region. The water from Uma Oya River will be linked through an approximately $3.7 \mathrm{~km}$ long link tunnel (conveyance tunnel) into the reservoir of the Dyraaba dam built on Mahatotilla Oya River. From this reservoir, a 15.55 $\mathrm{km}$ long head-race tunnel and a $628 \mathrm{~m}$ high vertical shaft

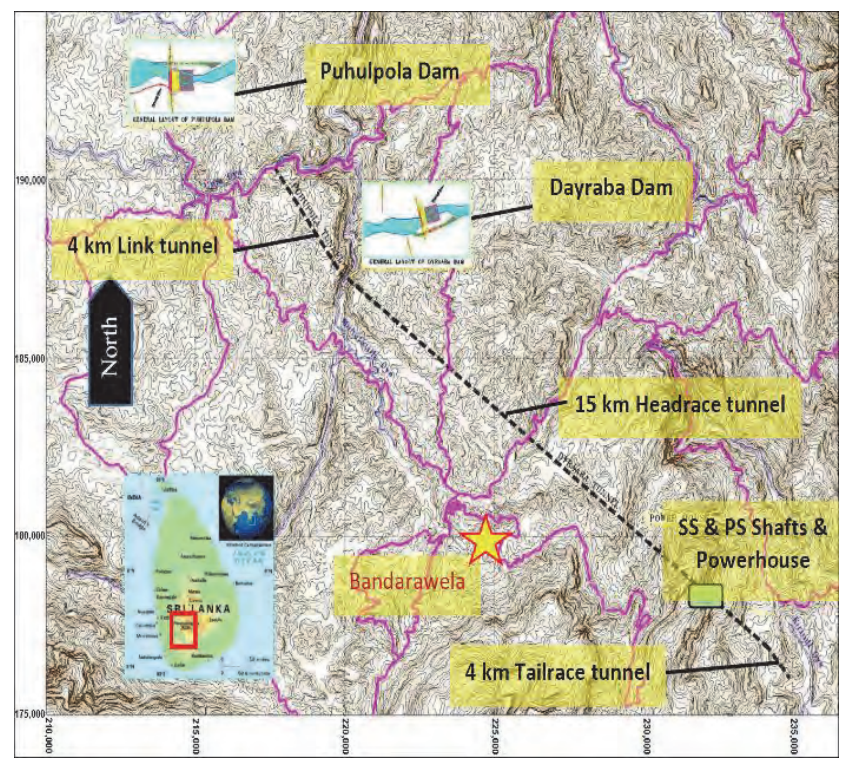

Fig. 4. Overview of the Uma Oya Multipurpose Development Project area, modified [4]. 
will convey water to the underground powerhouse. The discharge from the powerhouse will be directed into Alikota Oya River through an approximately $3.6 \mathrm{~km}$ long tailrace tunnel.

\section{E) Geology background}

The project is located in the so-called Highland Complex geological unit covering the central part of Sri Lanka. This complex has been strongly tectonised and comprises mixed ortho and para gneissic granulite units which structurally overlies amphibolite grade rocks of Vijayan complex to the east and southeast.

The Highland Complex covers the whole project area. The main types of rock consist of Precambrian metasedimentary rocks and charnockitic-gneisses, formed under high grade metamorphism. The metasedimentary rocks comprise garnet sillimanite gneisses, quartzites, quartz-feldspar granulites, garnet gneisses, marble and impure crystalline limestone. Charnockitic gneisses are the most common rock types of the Highland Complex [4].

Main geological structures within the project area comprise the occurrence of domes, basins and, anticline and syncline structures. Lineaments identified from aerial photographs suggest that they belong to three different sets running approximately north-south, northwest-southeast and northeast-southwest. These features could be either major fractures or faults, however, there is not enough evidence of displacement to identify them as faults. Experience elsewhere in the central part of Sri Lanka strongly suggests them to be prominent fractures or narrow shear zones [4].

\section{F) Objectives}

The objective of this case study is to contrast the geological prediction of at least $130 \mathrm{~m}$ ahead of the face obtained from the seismic investigation at two campaigns against the encountered geology after excavation. Due to the known high risk of water ingress, particular emphasis is made on the analysis of derived parameters that could help identifying such zones.

\section{G) Approach}

Due to the construction methodology of the HRT with installation of segmental lining right after excavation and limited access to the face, a continuous geological mapping is limited. For the subsequent discussion, two TSP campaigns are presented (Campaign \# 20 and \#21), for which complete geological profiles are available. Additionally, information of probe drills, particularly related to water presence, is also available. Fig. 5 shows the location of the two campaigns \#20 and \#21 upon the geological profile forecast. Note that the heading follows a decreasing stationing.

The TSP measurements have been carried out using the system Amberg TSP 303 Plus. 24 shots holes are drilled in one tunnel wall and small explosive charges are introduced on them which act as seismic sources. Four boreholes are drilled on both side of tunnel wall in which the seismic sensors are two metres depth installed "Fig. 5". The method is completely non-destructive and non-damaging. Once the system has been fully deployed, a first shot in the borehole closest to the receivers is blast to test the energy propagation. Afterwards, single blasts at each hole are sequentially performed. Seismic data can be view during acquisition on the screen of TSP software for data quality control purposes.

TSP acquired data have been processed with the latest 3D-technology of TSP 303 Plus software. In general, the aim of seismic data processing is an extraction and enhancement of the reflected wave field. For this purpose, the data have been run through a given number of specially designed processing steps, where intermediate results are stored enabling a review during processing at any time. The subsequent wave separation process separates the recordings into wave types according to their polarisation type.

Finally, the last step of the processing flow automatically extracts dominant reflector elements, which can be presented in $2 \mathrm{D}$ or $3 \mathrm{D}$ views with a reflective layer extraction of $\mathrm{P}$-waves, $\mathrm{SH}$-waves and $\mathrm{SV}$-waves and all geotechnical parameters calculated during processing of data. During the interpretation of results, the rock formations are divided mainly depending on P-wave data and elastic modules. Here, only more prominent reflection signals ahead of the tunnel face have been taken into account.

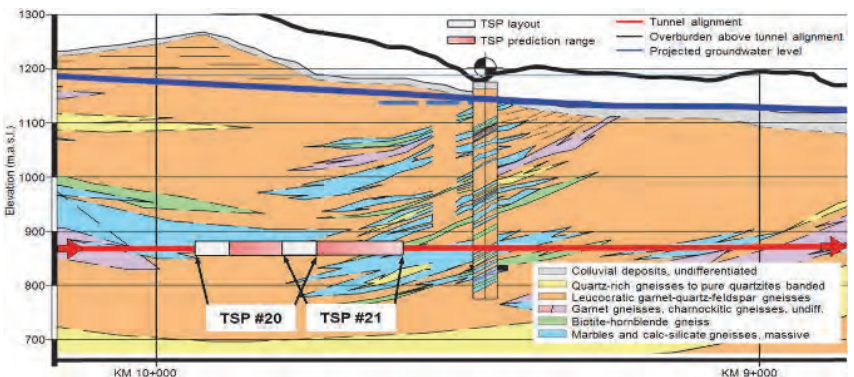

Fig. 5. Location of TSP campaigns \#20 and \#21 upon the geological forecast section between TM 10+000 and TM 9+000. Previous and later campaigns are not shown.

TABLE I. DETAILS OF TSP CAMPAIGNS

\begin{tabular}{|c|c|c|c|c|c|}
\hline Campaign & Date & $\begin{array}{c}\text { Face } \\
\text { Pos. } \\
(\mathbf{m})\end{array}$ & $\begin{array}{c}\text { Shot } \\
\mathbf{s}\end{array}$ & $\begin{array}{c}\text { Charge } \\
\mathbf{( g )}\end{array}$ & $\begin{array}{c}\text { Overburde } \\
\mathbf{n} \\
(\mathbf{m})\end{array}$ \\
\hline$\# 20$ & 15.02 .2016 & 9,781 & 23 & $30-80$ & 414 \\
\hline$\# 21$ & 16.03 .2016 & 9,630 & 20 & $30-70$ & 370 \\
\hline
\end{tabular}

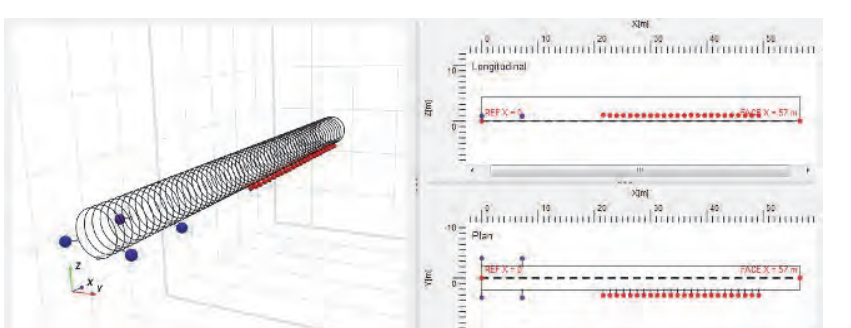

Fig. 6. TSP layout of campaign \#20 with Reference at TM 9,838 m and tunnel face location at TM 9,781 m. Blue dots indicate seismic 3Creceivers and red dots indicate the seismic source (shots holes) 


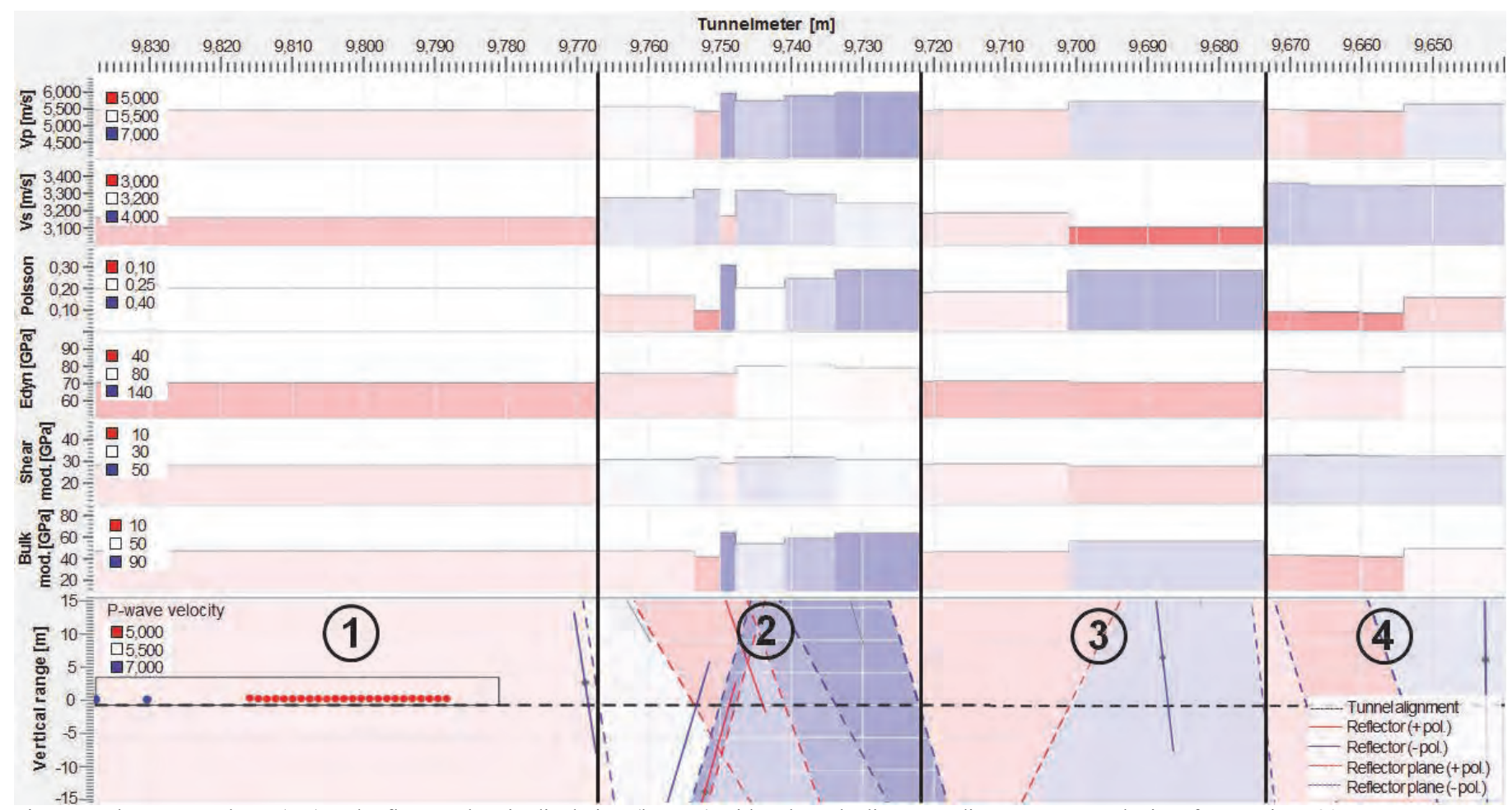

Fig. 7. Rock Property charts (top) and reflectors' longitudinal view (bottom) with colour shading according to P-wave velocity of Campaign \#20

\section{V. . RESULTS}

\section{1) Campaign \#20 (prediction range $146 \mathrm{~m}$ )}

In the TSP layout, reference P- and S-wave velocities are estimated as $V_{p}=5,470 \mathrm{~m} / \mathrm{s}$ and $V_{s}=3,160 \mathrm{~m} / \mathrm{s}$, respectively. These reference velocities correspond to the direct wave traveling from the shot holes to the receiver; hence, they are representative of the prevailing geology within the layout which in this case corresponds to inter-layering of biotite gneiss and garnet with garnet quartz feldspar gneiss characterised by moderate to high joint density, weathered rock and water presence. A reference $E_{d y n}=70 \mathrm{GPa}$ was estimated. According to the knowledge gained from previous TSP results, $E_{d y n}<80 \mathrm{GPa}$ indicates moderate to poor rock conditions which are in good agreement with the observed geology along the TSP layout for this campaign. Based on estimated $V_{p}$ and $V_{s}$ and geomechanical parameters ahead of the face, four major sections were identified as shown in "Fig. $7 "$.

- Section 1 (TM 9+838 to 9+767): This section represents the conditions along the TSP layout and spans until approximately $14 \mathrm{~m}$ ahead of the face. Compared to the previous campaign (\#19, not shown), decreased $E_{d y n}(70$ $\mathrm{GPa}$ ) and seismic waves velocities is found. These lower values reflect the jointed, weathered rock and partly water bearing rock occurring between receivers.

- Section 2 (TM 9+767 to 9+722): Slightly increasing seismic wave velocities result in a recurrent increase in the $E_{d y n} . V_{p}$ and $V_{s}$ reach values up to $5,983 \mathrm{~m} / \mathrm{s}$ and $3,316 \mathrm{~m} / \mathrm{s}$, respectively, while the $E_{d y n}$ increases up to $80 \mathrm{GPa}$ indicating improving rock stiffness. Hence, favourable rock condition can be expected. From TM 9+750, $V_{s}$ decreases down to 3,169 resulting in an increase of the

- Section 3 (TM 9+722 to 9+674): Seismic velocities and $E_{d y n}$ decrease to values similar as in the TSP layout $\left(V_{p}=\right.$ $\left.5,438, V_{s}=3,182, E_{d y n}=71\right)$. Similar rock conditions as in the TSP layout, i.e. high jointing and weathered rock, can be expected. The increment in Poisson ratio (0.29) observed from TM 9+701 until the end of the section can be associated to possible water bearing zone.

- Section 4 (TM 9+674 to 9+640 end of prediction): Along the first $20 \mathrm{~m}$, a slightly decrease in $V_{p}$ is found, however it increases from TM 9+654. In turn, $V_{s}$ increases markedly and remains uniform throughout the section $\left(V_{s}=3,345\right.$ $\mathrm{m} / \mathrm{s})$. The $E_{d y n}$ increases ranging between $77 \mathrm{GPa}$ and 80 $\mathrm{GPa}$, indicating slightly improving rock stiffness.

\section{2) Campaign \#21(prediction range $147 \mathrm{~m}$ )}

In the TSP layout, reference P- and S-wave velocities are estimated as $V_{p}=5,678 \mathrm{~m} / \mathrm{s}$ and $V_{s}=3,282 \mathrm{~m} / \mathrm{s}$, respectively. The prevailing geology within the layout corresponds to interlayering of biotite gneiss and garnet with garnet quartz feldspar gneiss varying from fresh to very slightly and moderately weathered rock at some sections and a zone with water seepage. A reference $E_{d y n}=78 \mathrm{GPa}$ is estimated. Compared to Campaign \#20, the $E_{d y n}$ increased possibly due to the fresh rock at some sections within the layout. However, this value is still a little low in comparison to some previous campaigns. According to the face mapping, some jointing and moderate rock conditions are also found. Based on estimated 


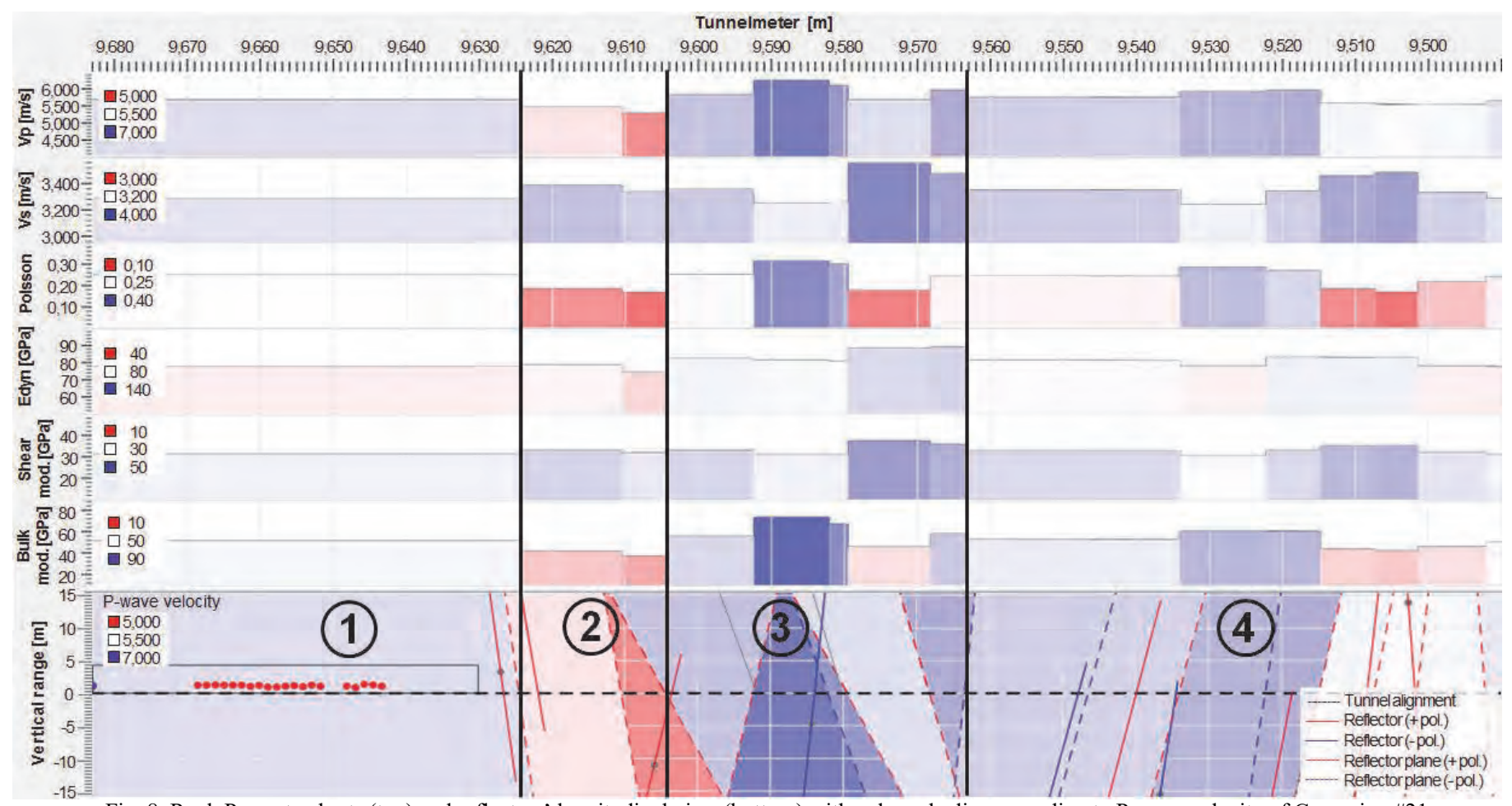

Fig. 8. Rock Property charts (top) and reflectors' longitudinal view (bottom) with colour shading according to P-wave velocity of Campaign \#21

$V_{p}$ and $V_{s}$ and geomechanical parameters ahead of the face, four major sections were identified as shown in "Fig. 8".

- Section 1 (TM 9+683to 9+625): This section represents the conditions along the TSP layout and spans until approximately $6 \mathrm{~m}$ ahead of the face. Compared to the previous campaign (\#20), increased $E_{d y n}(78 \mathrm{GPa})$ and seismic waves velocities are found. These higher values reflect the fresh rock mass found at some areas along the layout. However, still jointed, weathered rock and partly water bearing rock occurs.

- Section 2 (TM 9+625 to 9+604): Similar values for Edyn and S-wave velocity $($ Edyn $=79 \mathrm{GPa}, \mathrm{Vs}=$

$3,385 \mathrm{~m} / \mathrm{s}$ ) as in reference, however Vp drops to 5,283 $\mathrm{m} / \mathrm{s}$ towards the end of the section resulting in slightlydecreased $E_{d y n}=74 \mathrm{GPa}$. The latter indicates a slightly decrease in rock stiffness likely due to a higher joint density.

- Section 3 (TM 9+604 to 9+563): Throughout this section an increment of $V_{p}$ is observed (up to 6,249 $\mathrm{m} / \mathrm{s}$ ), which also results in an increment of $E_{d y n}$ (up to $88 \mathrm{GPa}$ ) indicating improving rock stiffness. Since $E_{d y n}$ is higher than $80 \mathrm{GPa}$, it can be inferred that this section most likely comprises moderate to good rock mass. However, in spite of the moderate increment of $V_{s}$, from TM 9+593 to $9+580$, it drops afterwards with a Poisson ratio larger than 0.32 indicating possible water ocurrence, likely due to the presence of single fractures.
- $\quad$ Section 4 (TM 9+563 to 9+490 end of prediction): A decrease in both waves velocities and $E_{d y n}$ is found ( $V_{p}$ $\left.=5,756, V_{s}=3,351 \mathrm{~m} / \mathrm{s}, E_{d y n}=81 \mathrm{GPa}\right)$, indicating decreasing rock stiffness. From TM 9+534, $V_{s}$ and $E_{d y n}$ further drop indicating a possible fracture zone of about $12 \mathrm{~m}$. Since the Poisson ratio reaches 0.29 at this zone, possible water presence can be expected. From TM 9+522, velocities and $E_{d y n}$ slightly increase again. Towards the end, a similar drop in $V_{s}$ and $E_{d y n}$ is observed, however, since this area corresponds to the end of prediction interpreting such changes in term of rock conditions is not advisable due to the loss of seismic resolution.

\section{3) Comparison between TSP 303 prognosis and actual geology}

Fig. 9 shows the geological profile based on face mapping and the TSP charts $E_{d y n}, V_{p}$ and $V_{s}$ of Campaign \#20. Descriptions of the rock mass condition based on tunnel observations are presented upon the $E_{d y n}$ chart. The dotted red lines define the borders of each rock mass description. For comparison purposes, sections defined from the TSP results interpretation are also shown in light grey. Fresh and massive rock mass is found directly after the face at TM 9+781. TSP results for this section indicate rather low rock stiffness $\left(E_{d y n}\right.$ $70 \mathrm{GPa}$ ), Such low values are most likely controlled by the rock conditions along the TSP layout, with a moderate weathered zone of $10 \mathrm{~m}$ and water ingress (not shown) along a section of the shot line. The following area is characterised by fresh to very slightly weathered massive rock mass which is in 


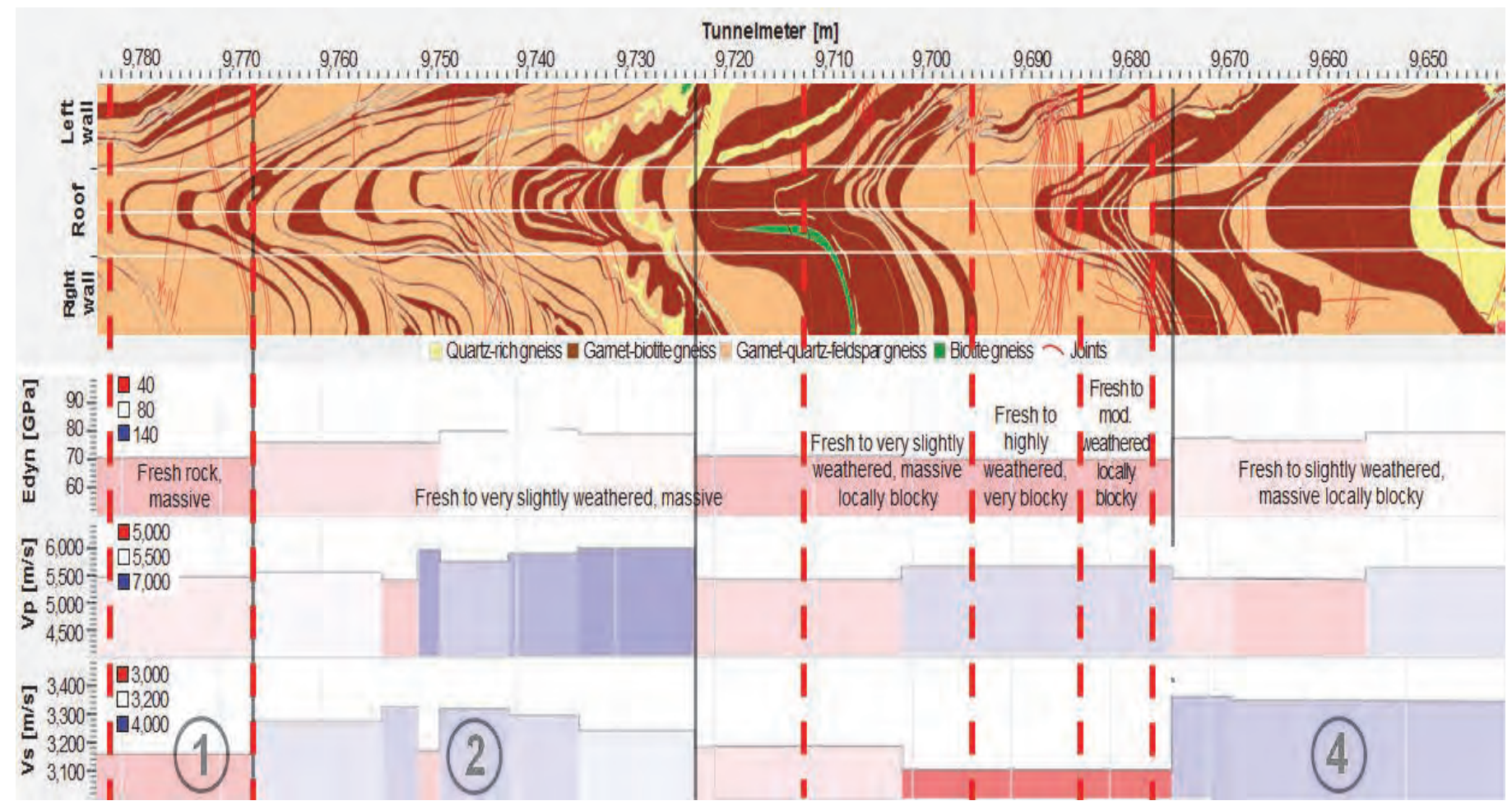

Fig. 9. Longitudinal profile (top) and TSP charts $E_{d y n}, V_{p}$ and $V_{s}$ along the prediction range for Campaign \#20. Rock condition description as extracted from the face mappings are shown upon the $E_{d y n}$ chart. The red dotted line defines the section borders for each description. TSP sections described in the previous chapter are shown in light grey (circle with number)

good agreement with Section 2 of the TSP prognosis with recurrent increasing rock stiffness. Towards the end (TM 9+722 approx.), TSP results already indicate a transition to less favourable conditions. From TM 9+711, rock conditions change to fresh to very slightly weathered and locally blocky, followed by highly and moderately weathered very blocky tolocally blocky rock mass characterised by a higher joint density. This area is in good agreement with section 3 of the TSP results. In particular, $V_{s}$ decreases markedly within the area of higher jointing. The rock conditions improve from TM 9+976 until the end of the prediction with fresh to slightly weathered massive and locally blocky rock with lesser jointing occurrence. This last segment is in good agreement with prognosis of Section 4.

Fig. 10 shows the geological profile based on face mapping and the TSP charts Edyn, $V_{p}$ and $V_{s}$ of Campaign \#21. The first two descriptions indicate fresh to slightly weathered and completely weathered rock conditions, massive to locally blocky and blocky rock mass. As shown by the estimated $E_{d y n}$, both descriptions are in good agreement with the TSP prognosis in Sections 1 and 2, moreover, the borders of the sections fits very well with those of the descriptions. Compared to Campaign \#20, seismic velocities are rather higher, however, changes in the velocities still reflects the rock condition variations along this segment. Hence, the higher joint density is reflected in the lowering of $V_{s}$. The following description starting at TM 9+600 denotes fresh to slightly weathered rock for the next $55 \mathrm{~m}$ approx. which is in good agreement with Section 3 and approximately the first 10 m of Section 4 of the TSP prognosis, where an improvement in the rock stiffness was predicted. The next description starting at TM 9+546 points out slightly to highly weathered and highly blocky rock, characterised by a very high joint density in the middle of this segment. In this case, a satisfactory agreement with Section 4 is observed. TSP results indicate slightly changes (decreasing rock stiffness) with a possible fracture zone starting at TM 9+534. This zone fits very well the area with the highest joint density where $V_{s}$ response to the jointing is apparently more sensitive than $V_{p}$. The agreement at the end of the prediction is also satisfactory, however, it should be consider that the seismic resolution at this distance has reduced considerably.

\section{4) Water exploration by means of TSP results}

Groundwater inflow has posed one of the biggest challenges throughout the project. On Dec. 24th at TM $11+160$, a high water inflow of about $400 \mathrm{l} / \mathrm{s}$ nearly flooded the cutter head causing larger downtimes and requiring additional provisions. TSP measurements were not done when approaching this area. After this event, the use of TSP was intensified and performed systematically. "Fig. 11" shows the TSP Poisson ratio chart (top) with interpreted possible water bearing zones (middle) for Campaign \#20. At the figure bottom, segments with water ingress observed at various probe drills are presented. The entire TSP prediction range was covered by 11 probes starting at different tunnel meters and face positions (in hours). Water ingress ( $>4 \mathrm{l} / \mathrm{s}$ ) along the TSP layout was detected. In term of TSP results, at this section no 


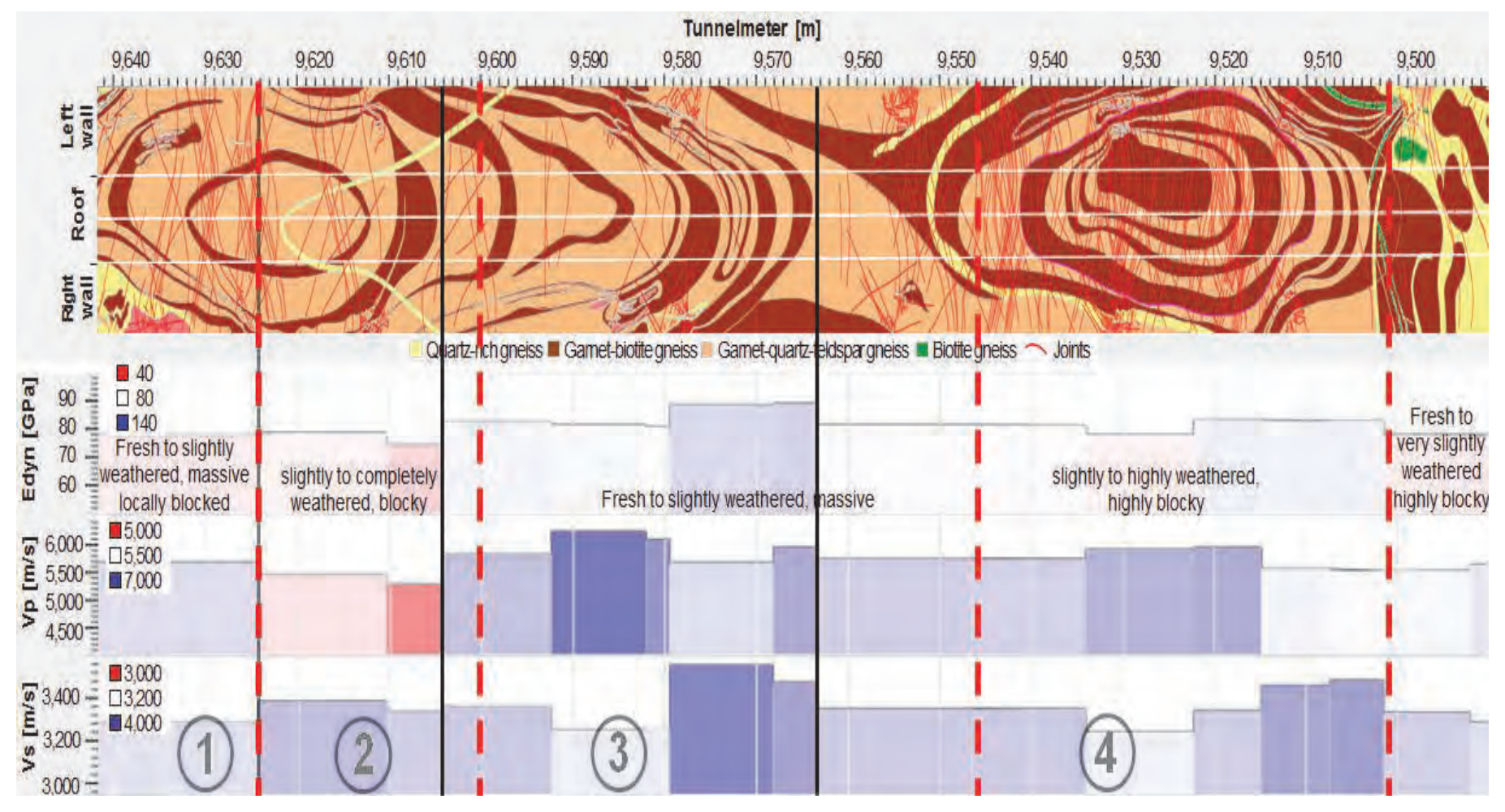

Fig. 10. Longitudinal profile (top) and TSP charts $E_{d y n}, V_{p}$ and $V_{s}$ along the prediction range for Campaign \#20. Rock condition description as extracted from the face mappings are shown upon the $E_{d y n}$ chart. The red dotted line defines the section borders for each description. TSP sections described in the previous chapter are shown in light grey (circle with number)

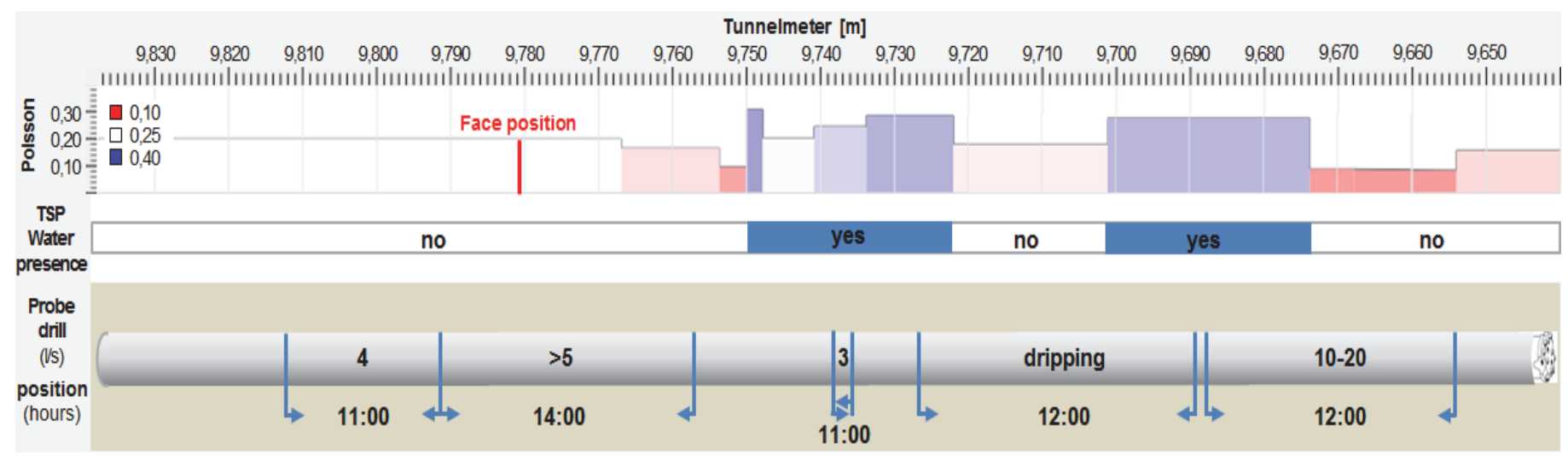

Fig. 11. TSP charts of Poisson ratio along the prediction range for Campaign \#20 (top). Segments in blue are interpreted as possible water bearing zone (middle). Water detected by different probe drills projected into a single probe spanning along the total explored length (bottom). Water ingress from probe drills in $1 / \mathrm{s}$, the number below each section represents the probe position at the face in time (hours clockwise)

prediction is done since the $\mathrm{Vp} / \mathrm{Vs}$ ratio is prescribed. In turn, ahead of the face, two sections with possible water bearing formations were predicted (TM 9+750 to 9+722 and 9+701 to 9+974). In the probe drills, a $2 \mathrm{~m}$ segment with 3 $1 / \mathrm{s}$ water ingress was detected starting at TM $9+739$. The second segment of about $32 \mathrm{~m}$ starting at TM 9+689 reported 10 to $20 \mathrm{l} / \mathrm{s}$. Between these two segments water dripping was documented. Both detected segments are within the TSP predicted water bearing zones. However, in the TSP results both zones were identified "earlier" and following this interpretation, probe drills were executed before reaching both zones accordingly. Hence, the conservative interpretation of the TSP data helped to avoid any unforeseen risk while the excavation.

\section{CONCLUSIONS}

The result and their comparison with excavated geology proved TSP 303 a more efficient and more reliable tool to obtain the advance 3D geological investigation. Data acquisition does not delay or effect the tunnel operation and can be performed on a continuous basis. As shown in the case study, TSP results delivered prognosis that are in good agreement with observed geological conditions after excavation. However, the low rock physical property contrasts, in particular acoustic impedance of the rock (i.e. 
product of rock density and seismic velocities) and the spatial disposition of layering and of some fractures (parallel to the tunnel) have posed a challenge when interpreting the TSP data.

In order to avoid more unforeseen risks during excavation, probe drills and TSP measurements performed systematically has resulted in a safer excavation, helping the site engineers to prepare on time grouting activities, safe parking position for the TBM among others.

In any hydropower projects, tunnel excavation can suffer due to uncertain geology, TSP 303 applications are the right way to turn the geological risk into manageable risk. With detection rates of $80-90 \%$ of rock formation changes and jointing an accuracy of the detection location lies inbetween \pm 1 to 5 meters at near to far offsets.

Geology always plays a major role in the planning stage, so there must be proper investigations to be carried out by advanced 3D Tunnel Seismic Prediction technology on a continuous basis

\section{ACKNOWLEDGMENT}

We would like to thanks Farab Company for approval to publish this case study and Amberg Engineering AG for supporting while the preparation of this article.

\section{REFERENCES}

[1] P.A. Scherwey, "The future of TBM tunnelling in hydroelectric projects," Proc. of the World Tunnel Congress 2013, Geneve, Taylor \& Francis Group, London, 1836-1842, 2013

[2] T. Dickmann, "The Role of Tunnel Seismic prediction in a Tunnelling projects: best practises," Indorock-2014: Fifth Indian Rock Conference, 12-14 November 2014, Delhi, India, 2014.

[3] T. Dickmann and D. Krueger, "How to turn geological uncertainty into manageable risk," Proc. of the World Tunnel Congress 2014 Tunnels for a better Life, 9-15 Mai 2014, Foz do Iguaçu, Brazil, 2014.

[4] A. Rahbar and J. Rostami, "Construction of Headrace Tunnel of Uma Oya Water Conveyance Project, Sri Lanka," Proc. of the World Tunnel Congress 2016, 22-28 April 2016, San Francisco, USA, 2016. 